\title{
MORPHOMETRIC ASSESSMENT OF HUMAN CORPUS CALLOSUM AND ITS CORRELATION WITH AGE AND GENDER- A MRI STUDY
}

\author{
Veena Nair1, Usha Devi Keezhathil Bhargavi²
}

${ }^{1}$ Assistant Professor, Department of Anatomy, MOSC Medical College, Kolenchery, Cochin.

${ }^{2}$ Additional Professor, Department of Anatomy, Government Medical College, Trivandrum.

\section{ABSTRACT}

\section{BACKGROUND}

The Corpus Callosum (CC) has been a topic of controversy with regards to the subject of sexual dimorphism. Findings regarding age-related changes are also not same in various studies conducted. Most of the studies have been done on western population with very few on Indian subjects. This MRI study was carried out in South Asian population of Kerala origin with a large sample size of 300 people.

The aim of the study is to measure and analyse the age and gender-related differences in the size of human CC with MR imaging of brain.

\section{MATERIALS AND METHODS}

This observational study was done with a sample of 300 normal subjects who underwent MRI scan at the Department of Radiodiagnosis, Government Medical College, Alappuzha. Data was segregated on gender and age basis and various morphometric parameters of CC were statistically analysed using SPSS version 16.

\section{RESULTS}

It was observed that length of CC increased throughout life. Thickness of genu and body were observed to increase up to 45 years, whereas thickness of splenium increased up to 55 years with a decline thereafter. No significant gender differences were found in most of the parameters analysed.

\section{CONCLUSION}

Although, the study consisted of a larger sample, no key sex differences were observed in CC in most of the parameters studied. This suggests that the gender-related differences in connectivity may not be due to gender differences in morphology of CC. Agerelated thinning was observed in anterior part of CC, a decade earlier than its posterior part.

\section{KEYWORDS}

Corpus Callosum, Gender Differences, Morphology, Connectivity, MRI, Splenium, Sexual Dimorphism, Age.

HOW TO CITE THIS ARTICLE: Nair V, Bhargavi UDK. Morphometric assessment of human corpus callosum and its correlation with age and gender- A MRI study. J. Evolution Med. Dent. Sci. 2017;6(57):4261-4266, DOI: 10.14260/Jemds/2017/923

\section{BACKGROUND}

The Corpus Callosum (CC) has always been the epicentre of a lot of debate and research following a report published by de Lacoste-Utamsing and Holloway ${ }^{1}$ that claimed females to have a significantly larger splenium area. Since then, numerous studies have been conducted to study the age and gender changes seen in the CC. Several studies have found significant sex differences in length, shape and volume of CC with females having larger relative splenial width. On the contrary, there are studies, which nullify such gender differences. Conclusions regarding age changes in the CC have also not been reliable among the various studies done. The word Corpus Callosum (CC) in Latin means "a body, which is tough." It is a structure present in advanced mammalian brain in the depth of longitudinal fissure. It is the largest commissure of white matter seen in the human brain and is

Financial or Other, Competing Interest: None.

Submission 10-06-2017, Peer Review 04-07-2017,

Acceptance 10-07-2017, Published 17-07-2017.

Corresponding Author:

Dr. Veena Nair,

MRRA 46-B, Mannam Road, Kunnumpuram,

Edappally North P.O., Cochin, Kerala.

E-mail: veenasruthy@gmail.com

DOI: $10.14260 /$ jemds $/ 2017 / 923$ made up of more than 200 million contralateral axonal projections. The CC is the main connector that is responsible for interhemispheric communications. It is about $10 \mathrm{~cm}$ long and consists of body, rostrum, genu and splenium. Splenium is the thickened posterior end of CC and lies about $6 \mathrm{cms}$ in front of occipital pole. Genu is most anteriorly projecting part and lies about $4 \mathrm{cms}$ behind the frontal pole in between the two lies the body of CC. The rostrum is the narrowest part that projects posteriorly from the genu. ${ }^{2}$

MR imaging allows study of CC in greater detail ${ }^{3,4}$ and with improved accuracy. Several imaging studies have shown the mid sagittal area of CC to show differences in morphology in relation to gender, handedness, ageing and pathological conditions. ${ }^{4,5}$ The CC has been shown to be affected in conditions such as schizophrenia, Alzheimer's and dyslexia even when the MR images reveal normal findings. Hence, measurements of CC have been proposed as useful pointers of disease progression.6,7,8,9,10 Very few studies have been performed in Indian population.11,12,13 The present study has been conducted using MRI scans to get a comprehensive data and to find out gender and age-related differences of CC in the population of Kerala.

\section{MATERIALS AND METHODS}

1. The sample for this observational study included the patients who were subjected to magnetic resonance 
imaging at the department of Radiodiagnosis at Government T.D. Medical College, Alappuzha. A total of 300 patients were selected for the study. Patients included were those with anatomically normal brain who underwent MRI for clinical conditions not known to cause any changes in the normal dimensions of CC like headaches, dizziness, hearing loss, infarcts, e.t.c.

2. The patients were studied using MRI in mid sagittal plane by using a 1.5 Tesla machine of GE Company from January 2012-July 2013. The patients belonged to both sexes of different age groups ranging from birth to 85 years.

The MRI scans of 300 subjects (148 males and 152 females) were studied. The data was collected in a standard proforma. Name, age, gender and address of patients were noted and the measurements were recorded in millimetres. The scan film showing mid-sagittal section of brain passing through the CC was chosen for measurement. The following measurements were taken.

\section{Measurements}

Length of CC (LCC)- An anterior most point and a posterior most point were taken on the CC. The distance between the two was measured as length of CC.

- Distance between anterior point and frontal lobe (AF) From the anterior most point, a horizontal line was drawn towards the maximum convexity of frontal lobe (Figure 1).

- Distance between posterior point and occipital lobe (PO)From the posterior most point, a straight line was drawn towards the maximum convexity of occipital lobe (Figure 1).

- Length of the Brain (LB)- The distance was taken between the points $\mathrm{F}$ and $\mathrm{O}$ (Figure 1 ).

- AS- The shortest distance between anterior most point and the superior border of frontal lobe was measured (Figure 1).

- PS- Similarly, the shortest distance between posterior most point and superior border of occipital lobe was measured (Figure 1).

- Maximum thickness of genu, rostrum and splenium was measured (Tg, Tr, Ts) (Figure 2).

- Maximum Thickness of Body (Tb) was taken at its midpoint $(\mathrm{M})$, which was taken at the centre of the length of CC (Figure 2).

\section{Ratios}

1. Length of CC/length of brain - LCC/LB.

2. Thickness of body at midpoint/length of CC - Tb/LCC.

3. Maximum splenial thickness/length of CC - Ts/LCC.

4. Maximum splenial thickness/length of brain - Ts/LB.

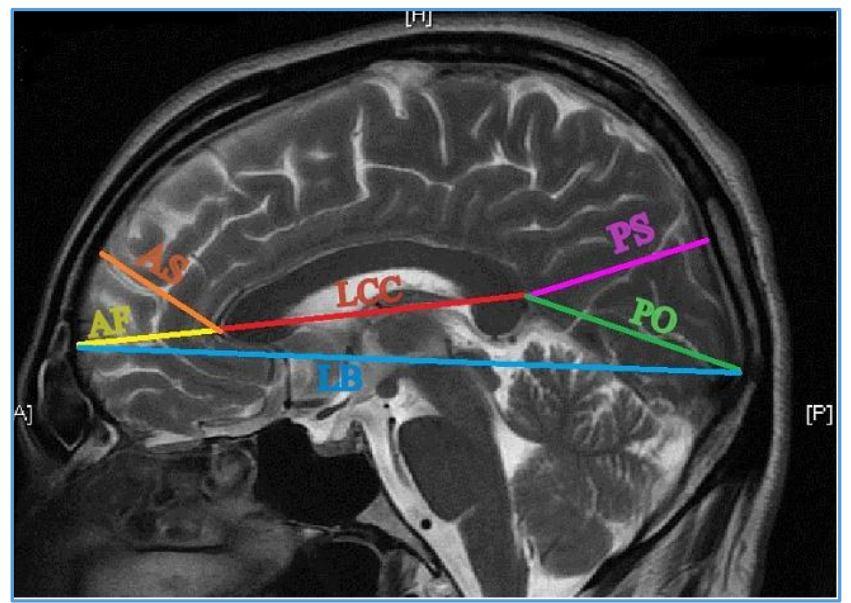

Figure 1. Mid Sagittal Section of Human Brain

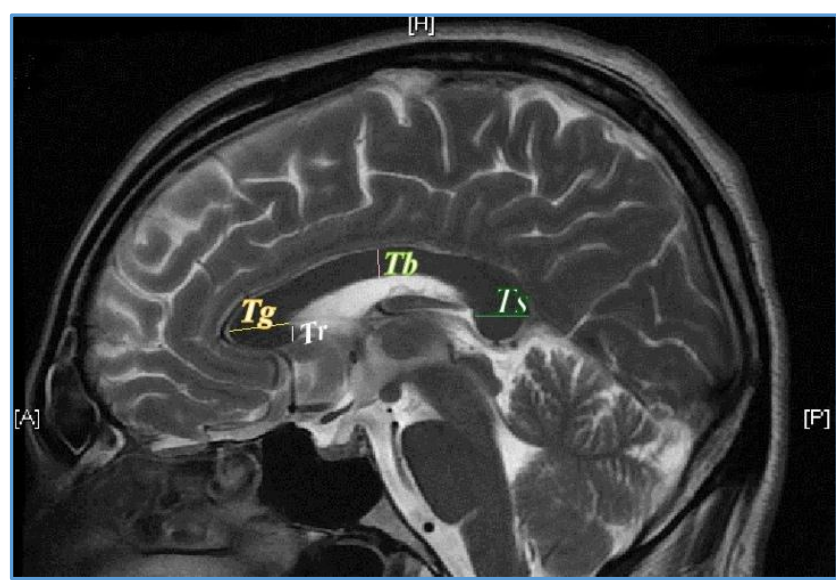

Figure 2. Mid Sagittal Section of Human Brain

All these dimensions were measured 3 times and an average value was taken. The measurements were taken using a marker calliper, which is software available in the computer. All these values were measured by a single observer. Finally, these measurements were correlated with age and gender. All these values were fed to the computer for detailed statistical analysis.

\section{Statistical Analysis}

The data obtained was entered in master charts. The range, arithmetic mean and standard deviation were calculated for quantitative data. To test the statistical significance of difference in the arithmetic mean between the male and female groups, independent sample t-test was used and Analysis of Variance (ANOVA) was done to assess the statistical significance of the difference in means among different age groups as it involved more than two groups. Statistical analysis was done using statistical software SPSS version.

\section{RESULTS}

\begin{tabular}{|c|c|c|c|c|c|c|}
\hline \multirow{8}{*}{$\mathrm{Tb}$} & Age & $\mathbf{N}$ & Mean & SD & $\mathbf{F}$ & p value \\
\hline & $<5$ & 25 & 4.41 & 0.96 & \multirow{7}{*}{8.649} & \multirow{7}{*}{0.001} \\
\hline & $5-9$ & 25 & 5.27 & 0.74 & & \\
\hline & $10-14$ & 29 & 5.49 & 1.00 & & \\
\hline & $15-24$ & 36 & 5.46 & 0.79 & & \\
\hline & $25-34$ & 42 & 6.02 & 1.06 & & \\
\hline & $35-44$ & 45 & 6.02 & 0.84 & & \\
\hline & $45-54$ & 48 & 5.62 & 1.13 & & \\
\hline
\end{tabular}




\begin{tabular}{|c|c|c|c|c|}
\hline & $55-64$ & 28 & 5.37 & 1.23 \\
\cline { 2 - 5 } & $>65$ & 22 & 4.78 & 0.99 \\
\cline { 2 - 5 } Total & $\mathbf{3 0 0}$ & $\mathbf{5 . 4 9}$ & $\mathbf{1 . 0 8}$ \\
\hline
\end{tabular}

Table 1. Comparison of Mean Tb Among the Various Age Groups

\begin{tabular}{|c|c|c|c|c|c|c|}
\hline \multirow{11}{*}{$\mathrm{Tg}$} & Age & $\mathbf{N}$ & Mean & SD & $\mathbf{F}$ & p value \\
\hline & $<5$ & 25 & 9.29 & 2.65 & \multirow{10}{*}{7.807} & \multirow{10}{*}{0.001} \\
\hline & $5-9$ & 25 & 11.19 & 1.67 & & \\
\hline & $10-14$ & 29 & 11.37 & 1.71 & & \\
\hline & $15-24$ & 36 & 11.36 & 1.47 & & \\
\hline & $25-34$ & 42 & 12.10 & 1.81 & & \\
\hline & $35-44$ & 45 & 12.22 & 1.66 & & \\
\hline & $45-54$ & 48 & 11.65 & 1.56 & & \\
\hline & $55-64$ & 28 & 11.48 & 2.07 & & \\
\hline & $>65$ & 22 & 9.99 & 2.20 & & \\
\hline & Total & 300 & 11.36 & 2.00 & & \\
\hline
\end{tabular}

\begin{tabular}{|c|c|c|c|c|c|c|}
\hline \multirow{11}{*}{ Ts } & Age & $\mathbf{N}$ & Mean & SD & $\mathbf{F}$ & p value \\
\hline & $<5$ & 25 & 7.88 & 2.47 & \multirow{10}{*}{9.772} & \multirow{10}{*}{0.001} \\
\hline & $5-9$ & 25 & 10.00 & 1.96 & & \\
\hline & $10-14$ & 29 & 10.37 & 1.32 & & \\
\hline & $15-24$ & 36 & 10.81 & 1.87 & & \\
\hline & $25-34$ & 42 & 11.20 & 1.76 & & \\
\hline & $35-44$ & 45 & 11.21 & 1.83 & & \\
\hline & $45-54$ & 48 & 11.45 & 1.83 & & \\
\hline & $55-64$ & 28 & 11.19 & 2.01 & & \\
\hline & $>65$ & 22 & 10.20 & 1.89 & & \\
\hline & Total & 300 & 10.66 & 2.09 & & \\
\hline
\end{tabular}

\begin{tabular}{|c|c|c|c|c|c|c|}
\hline \multicolumn{7}{|c|}{ LCC } \\
\hline Age & Sex & $\mathbf{N}$ & Mean & SD & $T$ & $\mathbf{P}$ \\
\hline \multirow{2}{*}{$<5$} & Male & 16 & 56.8 & 5.0 & \multirow{2}{*}{1.530} & \multirow{2}{*}{0.140} \\
\hline & Female & 9 & 52.7 & 8.6 & & \\
\hline \multirow{2}{*}{ 5-9 } & Male & 15 & 64.8 & 3.9 & \multirow{2}{*}{0.944} & \multirow{2}{*}{0.355} \\
\hline & Female & 10 & 63.4 & 3.2 & & \\
\hline \multirow{2}{*}{$10-14$} & Male & 20 & 66.4 & 5.2 & \multirow{2}{*}{-0.562} & \multirow{2}{*}{0.579} \\
\hline & Female & 9 & 67.4 & 2.0 & & \\
\hline \multirow{2}{*}{$15-24$} & Male & 12 & 67.4 & 3.6 & \multirow{2}{*}{0.352} & \multirow{2}{*}{0.727} \\
\hline & Female & 24 & 66.9 & 3.8 & & \\
\hline \multirow{2}{*}{$25-34$} & Male & 19 & 70.0 & 3.9 & \multirow{2}{*}{0.722} & \multirow{2}{*}{0.475} \\
\hline & Female & 23 & 69.1 & 3.8 & & \\
\hline \multirow{2}{*}{$35-44$} & Male & 20 & 74.1 & 4.1 & \multirow{2}{*}{3.107} & \multirow{2}{*}{0.003} \\
\hline & Female & 25 & 69.9 & 4.8 & & \\
\hline \multirow{2}{*}{$45-54$} & Male & 23 & 71.2 & 4.8 & \multirow{2}{*}{1.250} & \multirow{2}{*}{0.218} \\
\hline & Female & 25 & 69.7 & 3.5 & & \\
\hline \multirow{2}{*}{$55-64$} & Male & 16 & 72.5 & 5.4 & \multirow{2}{*}{0.730} & \multirow{2}{*}{0.472} \\
\hline & Female & 12 & 71.2 & 3.6 & & \\
\hline \multirow{2}{*}{$>65$} & Male & 7 & 72.6 & 4.4 & \multirow{2}{*}{0.315} & \multirow{2}{*}{0.756} \\
\hline & Female & 15 & 72.1 & 3.4 & & \\
\hline \multicolumn{7}{|c|}{$\begin{array}{l}\text { Table 4. Comparison of Mean LCC Among } \\
\text { Various Age Groups in Males and Females }\end{array}$} \\
\hline
\end{tabular}

\begin{tabular}{|c|c|c|c|c|c|c|}
\hline \multicolumn{7}{|c|}{ AS } \\
\hline Age & Sex & $\mathbf{N}$ & Mean & SD & $t$ & p \\
\hline \multirow{2}{*}{$<5$} & Male & 16 & 38.0 & 5.1 & \multirow{2}{*}{3.686} & \multirow{2}{*}{0.001} \\
\hline & Female & 9 & 29.2 & 6.8 & & \\
\hline \multirow{2}{*}{$5-9$} & Male & 15 & 36.0 & 2.7 & \multirow{2}{*}{1.253} & \multirow{2}{*}{0.223} \\
\hline & Female & 10 & 34.5 & 3.2 & & \\
\hline \multirow{2}{*}{$10-14$} & Male & 20 & 37.8 & 3.1 & \multirow{2}{*}{1.411} & \multirow{2}{*}{0.170} \\
\hline & Female & 9 & 36.0 & 3.3 & & \\
\hline \multirow{2}{*}{$15-24$} & Male & 12 & 34.2 & 3.7 & \multirow{2}{*}{0.486} & \multirow{2}{*}{0.630} \\
\hline & Female & 24 & 33.5 & 4.1 & & \\
\hline \multirow{2}{*}{$25-34$} & Male & 19 & 34.4 & 3.4 & \multirow{2}{*}{1.246} & \multirow{2}{*}{0.220} \\
\hline & Female & 23 & 33.0 & 3.5 & & \\
\hline
\end{tabular}

\begin{tabular}{|c|c|c|c|c|c|c|}
\hline \multirow{2}{*}{$35-44$} & Male & 20 & 34.9 & 2.6 & \multirow{2}{*}{2.057} & \multirow{2}{*}{0.046} \\
\cline { 2 - 6 } & Female & 25 & 33.1 & 3.0 & & \\
\hline \multirow{2}{*}{$45-54$} & Male & 23 & 33.5 & 3.6 & \multirow{2}{*}{1.224} & \multirow{2}{*}{0.227} \\
\cline { 2 - 6 } & Female & 25 & 32.3 & 3.2 & & \multirow{2}{*}{0.918} \\
\hline \multirow{2}{*}{$55-64$} & Male & 16 & 35.0 & 2.2 & \multirow{2}{*}{0.001} \\
\cline { 2 - 5 } & Female & 12 & 31.5 & 1.4 & & \multirow{2}{*}{0.437} \\
\hline \multirow{2}{*}{65} & Male & 7 & 34.6 & 2.3 & \multirow{2}{*}{0.793} & 0.4 \\
\cline { 2 - 5 } & Female & 15 & 33.8 & 2.4 & Table 5. Comparison of Mean AS Among \\
\hline \multicolumn{7}{|c|}{ Various Age Groups in Both the Sexes } \\
\hline
\end{tabular}

\begin{tabular}{|c|c|c|c|c|c|c|}
\hline \multicolumn{7}{|c|}{ PS } \\
\hline Age & Sex & $\mathbf{N}$ & Mean & SD & $\mathbf{t}$ & p \\
\hline \multirow{2}{*}{$<5$} & Male & 16 & 48.2 & 6.0 & \multirow{2}{*}{2.794} & \multirow{2}{*}{0.010} \\
\hline & Female & 9 & 40.2 & 8.2 & & \\
\hline \multirow{2}{*}{$5-9$} & Male & 15 & 48.0 & 4.9 & \multirow{2}{*}{0.401} & \multirow{2}{*}{0.692} \\
\hline & Female & 10 & 47.3 & 2.5 & & \\
\hline \multirow{2}{*}{$10-14$} & Male & 20 & 48.9 & 3.6 & \multirow{2}{*}{0.048} & \multirow{2}{*}{0.962} \\
\hline & Female & 9 & 48.8 & 2.4 & & \\
\hline \multirow{2}{*}{$15-24$} & Male & 12 & 48.0 & 3.4 & \multirow{2}{*}{1.546} & \multirow{2}{*}{0.131} \\
\hline & Female & 24 & 45.9 & 4.1 & & \\
\hline \multirow{2}{*}{$25-34$} & Male & 19 & 47.7 & 3.4 & \multirow{2}{*}{0.994} & \multirow{2}{*}{0.326} \\
\hline & Female & 23 & 46.6 & 3.3 & & \\
\hline \multirow{2}{*}{$35-44$} & Male & 20 & $\begin{array}{l}47.8 \\
\end{array}$ & 4.1 & \multirow{2}{*}{2.135} & \multirow{2}{*}{0.038} \\
\hline & Female & 25 & 45.6 & 2.8 & & \\
\hline \multirow{2}{*}{$45-54$} & Male & 23 & 47.9 & 3.1 & \multirow{2}{*}{3.407} & \multirow{2}{*}{0.001} \\
\hline & Female & 25 & 44.4 & 3.9 & & \\
\hline \multirow{2}{*}{$55-64$} & Male & 16 & 47.7 & 2.7 & \multirow{2}{*}{5.158} & \multirow{2}{*}{0.001} \\
\hline & Female & 12 & 42.9 & 2.0 & & \\
\hline \multirow{2}{*}{$>65$} & Male & 7 & 45.7 & 2.4 & \multirow{2}{*}{1.369} & \multirow{2}{*}{0.186} \\
\hline & Female & 15 & 43.9 & 3.1 & & \\
\hline
\end{tabular}

Table 6. Comparison of PS Across Age Groups in Both the Sexes

\begin{tabular}{|c|c|c|c|c|c|c|}
\hline \multicolumn{7}{|c|}{ LB } \\
\hline Age & Sex & $\mathbf{N}$ & Mean & SD & $t$ & $\mathbf{p}$ \\
\hline \multirow{2}{*}{$<5$} & Male & 16 & 146.4 & 10.9 & \multirow{2}{*}{2.877} & \multirow{2}{*}{0.009} \\
\hline & Female & 9 & 125.1 & 26.3 & & \\
\hline \multirow{2}{*}{$5-9$} & Male & 15 & 154.5 & 6.5 & \multirow{2}{*}{1.531} & \multirow{2}{*}{0.139} \\
\hline & Female & 10 & 150.9 & 4.7 & & \\
\hline \multirow{2}{*}{$10-14$} & Male & 20 & 157.4 & 7.3 & \multirow{2}{*}{-0.552} & \multirow{2}{*}{0.585} \\
\hline & Female & 9 & 158.9 & 5.7 & & \\
\hline \multirow{2}{*}{$15-24$} & Male & 12 & 156.0 & 5.7 & \multirow{2}{*}{1.232} & \multirow{2}{*}{0.226} \\
\hline & Female & 24 & 147.8 & 22.5 & & \\
\hline \multirow{2}{*}{$25-34$} & Male & 19 & 159.0 & 8.3 & \multirow{2}{*}{2.008} & \multirow{2}{*}{0.051} \\
\hline & Female & 23 & 154.6 & 5.8 & & \\
\hline \multirow{2}{*}{$35-44$} & Male & 20 & 162.6 & 8.1 & \multirow{2}{*}{4.229} & \multirow{2}{*}{0.001} \\
\hline & Female & 25 & 153.8 & 5.9 & & \\
\hline \multirow{2}{*}{$45-54$} & Male & 23 & 158.7 & 7.1 & \multirow{2}{*}{3.232} & \multirow{2}{*}{0.002} \\
\hline & Female & 25 & 152.5 & 6.3 & & \\
\hline \multirow{2}{*}{$55-64$} & Male & 16 & 161.5 & 9.2 & \multirow{2}{*}{3.380} & \multirow{2}{*}{0.002} \\
\hline & Female & 12 & 150.8 & 6.9 & & \\
\hline \multirow{2}{*}{$>65$} & Male & 7 & 159.7 & 4.1 & \multirow{2}{*}{2.901} & \multirow{2}{*}{0.009} \\
\hline & Female & 15 & 153.4 & 5.0 & & \\
\hline & $\begin{array}{l}\text { able } 7.0 \\
\text { he Vario }\end{array}$ & 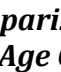 & of $N$ & of & mong & \\
\hline
\end{tabular}

\section{Observations}

In this study, the following parameters of CC showed age changes-

- The length of CC was found to increase with advancing age. Mean LCC in less than 5 years is $55.36 \pm 6.66 \mathrm{~mm}$, which increased gradually to $72.23 \pm 3.67 \mathrm{~mm}$ in more than 65 years.

- The thickness of body and genu were found to increase up to 45 years with a slight decline thereafter. The $\mathrm{Tb}$ 
increased from young age (less than 5 years), peaked between $25-45$ years $(6.02 \pm 0.84) \mathrm{mm}$ and thereafter gradually decreased with age. The mean value of $\mathrm{Tg}$ increased up to 45 years $(12.22 \pm 1.66) \mathrm{mm}$ thereafter declines with age.

- The thickness of splenium was found to increase up to 55 years after which there was a slight decline with age. Difference in mean Ts increased with age up to 55 years $(11.9 \pm 2.01) \mathrm{mm}$ after which it started declining with age (greater than 65 years, $10.2 \pm 1.89$ ) $\mathrm{mm}$.

- $\quad$ The AS $(37.23 \pm 3.20) \mathrm{mm}$ and PS (mean $=48.86 \pm 3.23$ ) $\mathrm{mm}$ increased up to 15 years after which the value decreased with age. The minimum value of AS is mean of $(32.06 \pm 2.32) \mathrm{mm}$ and PS is $(44.46 \pm 3.00) \mathrm{mm}$ in the age group $>65$ years.

- $\quad$ The FA increases up to 15 years $($ mean $=39.71 \pm 2.44$ ) mm with a decline with age thereafter. Mean value in $>65$ years is $35.68 \pm 2.37 \mathrm{~mm}$.

- The LB increases up to 15 years $(157.9 \pm 6.8) \mathrm{mm}$ after which the values remain unchanged. From 15 years onwards, no specific trend is seen. The mean values being variable. The mean value is minimum for the age group 15 - 25 years $(150.5 \pm 19.0)$.

- The ratio of LCC/LB increases up to 25 years after which the values are variable. It increases up to 25 years of age (mean $=0.4629 \pm 0.15) \mathrm{mm}$ beyond, which the values do not show a specific trend. The minimum mean value is seen in the age group of $<5$ years with mean of $0.4027 \pm$ $0.039 \mathrm{~mm}$.

- The ratio of Tb/LCC increases up to 35 years (mean value of $0.0869 \pm 0.0158$ ) $\mathrm{mm}$ with a slight decline thereafter to $0.0659 \pm 0.01246 \mathrm{~mm}>65$ years.

- The ratio of Ts/LCC increases up to 55 years age (mean = $0.1628 \pm 0.02531) \mathrm{mm}$ with a slight decline thereafter. Mean value in $>65$ years is $(0.1408 \pm 0.02303) \mathrm{mm}$.

- The ratio of Ts/LB increases up to 25 years $(0.0741 \pm$ $0.02265) \mathrm{mm}$ after which the values decline with age. The mean value in $>65$ years is $0.0656 \pm 0.1203 \mathrm{~mm}$.

- The following parameters showed gender differences.

- The length of CC is more in males of the age group 35-45 years $(74.1 \pm 4.1) \mathrm{mm}$. No gender difference is seen before and after this age group.

- The $\mathrm{Tb}$ is more in males in less than 5 years. No gender difference seen beyond this age group.

- No gender difference is seen in thickness of rostrum, genu and splenium.

- The mean AS, PS, AF, PO, LB is significant in males of less than 5 years.

- The mean AS is significant in males when compared to females in less than 5 years $(38 \pm 5.1) \mathrm{mm}$. Thereafter, significant difference was seen among the males as compared to females during 35-45 years $(34.9 \pm 2.6) \mathrm{mm}$ and $55-65$ years $(35 \pm 2.2) \mathrm{mm}$.

- The mean PS is significant in males when compared to females in less than 5 years $(48.2 \pm 6) \mathrm{mm}$. Thereafter, significant difference is seen among the males as compared to females till 35-65 years.

- The mean value of AF is significant in males as compared to females in less than 5 years $(39.9 \pm 5.7) \mathrm{mm}$. Thereafter, significant difference is seen among the sexes with males having larger values during 35-45 years and $55-65$ years $(36.3 \pm 2.3) \mathrm{mm}$.

- The mean PO is significant in males as compared to females in less than 5 years $(55.2 \pm 7.1) \mathrm{mm}$. Thereafter, significant sex differences are seen in males in the age group between 35-65 years and beyond.

- The mean LB is significant in males when compared to females in less than 5 years $(146.4 \pm 10.9) \mathrm{mm}$. Thereafter, significant difference is seen among the males as compared to females during 35-65 years and beyond.

- The ratio of LCC/LB is significant in females less than 5 years. It again becomes significant in females in the age group 55-65 years. The mean value is more in females as compared to males in less than 5 years $(0.43 \pm 0.05) \mathrm{mm}$. A significant difference is seen among the males and females with females showing larger values during 55-65 years $(0.47 \pm 0.02) \mathrm{mm}$.

- The ratio of $\mathrm{Tb} / \mathrm{LCC}$ is significant in males of the age group less than 5 years. Thereafter, no difference is seen among the sexes. The ratio is significantly high in males in less than 5 years $(0.08 \pm 0.01) \mathrm{mm}$. Thereafter, no significant difference is seen among the sexes with ageing.

- The ratio of Ts/LCC and Ts/LB is not significant among the sexes.

\section{DISCUSSION}

A lot of debate is centred on the morphology of CC in relation to age and sex. The main objective of this study is to measure, analyse and estimate the age-related changes and genderrelated differences in the population of Alappuzha. The baseline data thus obtained can be used by the neuroradiologists, neurologists, psychiatrists and basic medical scientists for research and clinical purposes.

\section{Age-Related Changes in Morphology of CC}

In our study, the absolute length of CC was found to increase with age, which was consistent with the findings of Suganthy $\mathrm{J}^{11}$ et al and Takeda $\mathrm{S}^{14}$ et al. This maybe because with advancing age, a person is more and more exposed to a complex and enriched environment resulting in an increase in afferent synapsal connections ${ }^{15}$ that in turn may lead to increase in length of $\mathrm{CC}$ with age. However, the relative increase in CC length, which is LCC/LB was seen only up to 25 years.

The thickness of the body of CC [Tb] and the thickness of genu [Tg] was seen to increase up to 45 years after which there was a gradual decline with age. Similarly, the thickness of splenium [Ts] was found to increase up to 55 years after which a gradual decline with age was noted. Among the callosal ratios, Ts/LB, Tb/LCC and Ts/LCC were noted to increase with age up to 25,35 and 55 years, respectively beyond which they decreased with age. This is in concordance with the findings of Lissette $\mathrm{J}^{16}$ who observed that older adults show age-related atrophy in the anterior and middle sections of the $\mathrm{CC}$, the posterior part does not appear to be susceptible to age-related atrophy. Weis ${ }^{17}$ et al also noted that genu and width of anterior parts of CC decreased significantly with ageing suggesting alteration in frontal and temporal interhemispheric fibre. Studies addressing callosal and structural interhemispheric function suggest that the efficiency of the interhemispheric transfer of information decreases with increasing age and this maybe 
one factor contributing to the wide range of cognitive, motor, visuoperceptual and communication-related difficulties experienced by ageing adults. ${ }^{18}$ This might be because of agerelated cortical atrophy, especially in frontal lobes ${ }^{19,20}$ resulting in loss of cortical neurons, which in turn causes secondary loss of callosal fibers. As the anterior parts of CC carry axons from the frontal, premotor and motor cortices, this age-related atrophy though relatively small is more in the anterior parts of CC than in the posterior parts.

The value of AS, PS, AF and LB increases up to 15 years, which can be attributed to the growth of the brain during the initial growing years. After that, the values of AS, PS and AF start declining gradually, whereas the length of the brain does not change. This may be due to the fact that the LCC increases throughout the age, thereby resulting in a relative decrease in the distances of AS, PS and AF. This is in concordance with the Monro-Kellie doctrine, which states that the cranial box is rigid and constant in volume and contains brain, blood and cerebrospinal fluid. If anyone of the constituents increases, the other two must diminish. Later on, cortical atrophy set in resulting in gradual decline in these values. Studies have shown that the rates of global atrophy in healthy people increase gradually with age from an annual rate of $0.2 \%$ a year at age $30-50$ to $0.3-0.5 \%$ at age $70-80 .{ }^{19}$

\section{Gender-Related Differences}

Many studies have shown sexual dimorphism in different parts of CC; however, none of them have demonstrated a consistent result. In this study, the mean LCC was more in men than women in all the age groups, but a statistically significant difference was seen only in the age group of 35-45 years ( $\mathrm{p}=0.003$ ). Gupta et $\mathrm{al}^{12}$ and Suganthy et al ${ }^{11}$ also noted men to have a longer CC among the Indian population. The gender difference may be attributed to the fact that men in their 30's and 40's are more active professionally as compared to their female counterparts, hence requiring increased recruitment and interhemispheric communication for efficient performance of the complex multiple tasks.

In our study, the mean $\mathrm{Tb}$ was more in males as compared to females in all groups, but a statistically significant difference was seen only in the age group of $<5$ years $(p=0.007)$. This is contrary to the findings of Allen L. S et al ${ }^{21}$ who did not find any significant sex differences in the CC of children aged 2-16 years. This difference observed in the early childhood maybe due to effect of the perinatal gonadal hormones, which are responsible for the sexual dimorphism in the foetuses. The axonal pruning 22 taking place later in the development may account for the lack of sex differences observed in other age groups. This was similar to the findings of Witelson ${ }^{23}$ who found anterior parts of body of CC to be larger in males. No gender differences were observed in the $\mathrm{Tg}$ and $\mathrm{Tr}$ in our study.

\section{Sexual Dimorphism in Splenium}

Many studies have reported an increase in size of splenium in females. In this study, although the mean Ts was more in females than males, a statistically significant difference was not observed. This was similar to the findings of Takeda ${ }^{14}$ and Suganthy ${ }^{11}$ et al who did their studies in Japanese and Indian populations, respectively. Our results do not correlate with the findings of Atif Aydenlioghi ${ }^{24}$ et al, Davatzikos ${ }^{25}$ et al and
Gupta $\mathrm{T}$ et al ${ }^{12}$ who demonstrated a robust sex difference in the splenium of females.

The values of AS, PS, AF, PO and LB were significantly higher in males as compared to females $(p=0.001)$. These were consistent with the findings of Gupta T et al.12 On subgroup analysis, all these parameters showed a statistical significant difference in males in the age group of less than 5 years. Also, as the age advances, statistically significant difference was observed in AS among males of the age group of 35-45 years and 55-65 years. Likewise, the value of AF, PS, $\mathrm{PO}$ and LB was also statistically significant in males in the age group 35-65 years.

The sex differences seen in early childhood maybe due to the fact that nearly all the sexually dimorphic parameters in the brain including CC are influenced by perinatal gonadal hormone levels. The gonadal hormones during a critical period of perinatal development may influence the survival of neurons and the number of axons coursing through the CC of humans. ${ }^{26}$ Probably, later in development, callosal axonal pruning22 may take place resulting in absence of any sex difference. The sex differences seen later in life maybe the result of a different ageing process that may occur in the brains of men than women mediated through hormonal 27,28 and environmental factors. ${ }^{29,30}$

Among the ratios, LCC/LB, Ts/LB were found to be statistically significant among the sexes with females showing higher values. Elster et $\mathrm{al}^{31}$ and Janacke ${ }^{32}$ et al also found the ratio of Ts/LB to be significantly high in females, which they attributed to the smaller size of their brain rather than the gender.

\section{CONCLUSION}

Thus, among the age-related changes, the anterior part of $\mathrm{CC}$ was found to be affected a decade earlier as compared to posterior part of CC. No gender-related differences were observed in most of the parameters studied. Though, our study is one that comprises a larger sample, we did not observe substantial sex differences in CC to propose that the gender-related differences in the hemispheric functions are due to gender differences in connectivity. This study provides analysed data to be used as reference for the neuroradiologists, neurologists, psychiatrists and neurobiologists for their clinical and research activities.

\section{ACKNOWLEDGEMENT}

I wish to thank Dr. Shobha Ramnarayan, Professor of Anatomy, for her valuable suggestions, able guidance and constant inspiration throughout the study. I extend my sincere thanks to all senior staff members of Government T.D. Medical College, Alappuzha, for their timely advice and support throughout the study. I also thank the Department of Radiodiagnosis for their immense technical support rendered during the work.

\section{REFERENCES}

[1] DeLacoste-Utamsing C, Holloway RL. Sexual dimorphism in the human corpus callosum. Science 1982;216(4553):1431-2.

[2] Standring S, Ellis H, Healy CJ, et al. Gray's anatomy: the anatomical basis of clinical practice. 39th edn. London: Elsevier Churchill Livingstone 2005:411-2. 
[3] Griffiths PD, Batty R, Reeves MJ, et al. Imaging the corpus callosum, septum pellucidum and fornix in children: normal anatomy and variations of normality. Neuroradiology 2009;51(5):337-45.

[4] Kocabiyik N, Kilic C, Baykal B, et al. Morphometric assessment of corpus callosum and cerebral hemispheres with magnetic resonance imaging. Balkan Medical Journal 2010;27(4):378-84.

[5] Moffat SD, Hampson E, Lee DH. Morphology of the planum temporale and corpus callosum in left handers with evidence of left and right hemisphere speech representation. Brain 1998;121(12):2369-79.

[6] Thomann PA, Wustenberg T, Pantel J, et al. Structural changes of the corpus callosum in mild cognitive impairment and Alzheimer's disease. Dementia and Geriatric Cognitive Disorders 2006;21(4):215-20.

[7] Tomimoto H, Lin JX, Matsuo A, et al. Different mechanisms of corpus callosum atrophy in Alzheimer's disease and vascular dementia. Journal of neurology 2004;251(4):398-406.

[8] Casanova MF, El-Baz A, Elnakib A, et al. Corpus callosum shape analysis with application to dyslexia. Translational neuroscience 2010;1(2):124-30.

[9] Micoulaud-Franchi J, Bat-Pitault F, Da Fonseca D, et al. Early onset schizophrenia and partial agenesis of corpus callosum. Archives de pédiatrie 2011;18(2):189-92.

[10] Downhill JE, Buchsbaum MS, Wei T, et al. Shape and size of the corpus callosum in schizophrenia and schizotypal personality disorder. Schizophrenia Research 2000;42(3):193-208.

[11] Suganthy J, Raghuram L, Antonisamy B, et al. Gender and age-related differences in the morphology of the corpus callosum. Clinical Anatomy 2003;16(5):396-403.

[12] Gupta T, Singh B, Kapoor K, et al. Age and sex related variations in corpus callosal morphology. Nepal Medical College Journal 2008;10(4):215-21.

[13] Gupta E, Lalwani R, Babu C, et al. Age related changes of corpus callosum by MRI in females. The Internet Journal of Neurology 2009;13(1):1-5.

[14] Takeda S, Hirashima Y, Ikeda H, et al. Determination of indices of the corpus callosum associated with normal ageing in Japanese individuals. Neuroradiol 2003;45(8):513-8.

[15] Markham JA, Greenough WT. Experience-driven brain plasticity: beyond the synapse. Neuron Glia Biol 2004;1(4):351-63.

[16] Knaap VDLJ, Ham VDIJ. How does the corpus callosum mediate interhemispheric transfer? A review. Behavioural Brain Research 2011;223(1):211-21.

[17] Weis S, Kimbacher M, Wenger L, et al. Morphometric analysis of the corpus callosum using MR: correlation of measurement with ageing in healthy individuals. Amer J Neuroradiol 1993;14:637-45.
[18] Bellis TJ, Wilber LA. Effects of aging and gender on interhemispheric function. J Speech Lang Hear Res 2001;44(2):246-63.

[19] Fox NC, Schott JM. Imaging cerebral atrophy: normal ageing to Alzheimer's disease. Lancet 2004;363(9406):392-4.

[20] Taki Y, Thyreau B, Kinomura S, et al. Correlations among brain gray matter volumes, age, gender, and hemisphere in healthy individuals. PloS one 2011;6(7):e22734.

[21] Allen LS, Richey YM, Chai YM, et al. Sex differences in the corpus callosum of the living human being. The Journal of Neuroscience 1991;11(4):933-42.

[22] Low LK, Cheng HJ. Axon pruning: an essential step underlying the developmental plasticity of neuronal connections. Philos Trans R Soc Lond B Biol Sci 2006;361(1473):1531-44.

[23] Witelson SF. Hand and sex differences in the isthmus and genu of the corpus callosum. A postmortem morphological study. Brain 1989;112(3):799-835.

[24] Aydlnlioglu A, Diyarbakirli S, Yüceer N, et al. The relationship of sex differences to the anatomy of the corpus callosum in the living human being. Turkish Neurosurgery 1996;6(1-2):1-4.

[25] Davatzikos C, Resnick SM. Sex differences in anatomic measures of interhemispheric connectivity: correlations with cognition in women but not men. Cerebral Cortex 1998;8(7):635-40.

[26] Nordeen EJ, Nordeen KW, Sengelaub DR, et al. Androgens prevent normally occurring cell death in a sexually dimorphic spinal nucleus. Science 1985;229(4714):671-3.

[27] de Bruin EA, Pol HE, Schnack HG, et al. Focal brain matter differences associated with lifetime alcohol intake and visual attention in male but not in female non-alcohol-dependent drinkers. Neuroimage 2005;26(2):536-45.

[28] Taki Y, Kinomura S, Sato K, et al. Relationship between body mass index and gray matter volume in 1,428 healthy individuals. Obesity 2008;16(1):119-24.

[29] Raz N, Rodrigue KM, Kennedy KM, et al. Hormone replacement therapy and age-related brain shrinkage: regional effects. Neuroreport 2004;15(16):2531-4.

[30] Erickson KI, Colcombe SJ, Raz N, et al. Selective sparing of brain tissue in postmenopausal women receiving hormone replacement therapy. Neurobiol Aging 2005;26(8):1205-13.

[31] Elster AD, Didersio DA, Moody DM. Sexual dimorphism of the human corpus callosum studied by magnetic resonance imaging: fact, fallacy and statistical confidence. Brain and Development 1990;12(3):321-5.

[32] Jäncke L, Staiger JF, Schlaug G, et al. The relationship between corpus callosum size and forebrain volume. Cerebral Cortex 1997;7(1):48-56. 